\title{
Is serum fibrinogen an affirmative marker for vaginal delivery without PPH?
}

\author{
Rachna Agarwal, Neha Jaiswal, Rajarshi Kar, Alpana Singh, Himsweta Srivastava \\ Correspondence: Dr. Rachna Agarwal, Professor. Department of Obstetrics and \\ Gynaecology, University College of Medical Sciences and Guru Teg Bahadur Hospital, Delhi; \\ Email - rachna_anila@yahoo.co.in
}

Distributed under Attribution-Non Commercial - Share Alike 4.0 International (CC BY-NC-SA 4.0)

\begin{abstract}
Objective: This study was conducted to see whether predelivery serum fibrinogen is a positive marker for conception ending with 'physiological' blood loss instead of predicting PPH. Methods: Low-risk pregnant women after 24 weeks of gestation with singleton pregnancy were prospectively followed for spontaneous vaginal delivery. Predelivery blood samples collected antenatally were preserved for estimation of serum fibrinogen. We excluded patients with altered coagulation profile, anemia, thrombocytopenia, hypertension, gestational diabetes and cholestasis. Final analysis compared fibrinogen levels in non-PPH and PPH subjects $(\mathrm{n}=40$ each). Results: The serum fibrinogen levels in non-PPH was $2.80 \pm 0.55 \mathrm{~g} / \mathrm{L}$ and in PPH group was $1.07 \pm 0.48 \mathrm{~g} / \mathrm{L}(\mathrm{p}<0.001)$. Correlation of predelivery fibrinogen and blood loss among subjects predicted a negative correlation $(\mathrm{r}=-0.695, \mathrm{p}<0.001)$. There were no PPH cases when serum fibrinogen level was $>2.63 \mathrm{~g} / \mathrm{L}$ (sensitivity $82.5 \%$, specificity $100 \%$ ). Conclusions: Prenatal serum fibrinogen level above $2.6 \mathrm{~g} / \mathrm{L}$ is suggested as potential alert marker for maternal well being (with non- $\mathrm{PPH}$ ) in vaginal delivery.
\end{abstract}

Keywords: Fibrinogen, pregnancy, blood loss, PPH.

Postpartum hemorrhage $(\mathrm{PPH})$ remains one of the foremost causes of maternal mortality and morbidity throughout the world. Looking to the growing awareness of haemostatic challenges in pregnant patients, serum fibrinogen is one of the key hematological parameters being investigated in relation to $\mathrm{PPH}^{1-7}$ Fibrinogen functions by activating platelet aggregation and initiating fibrin polymerization. Fibrinogen levels increase with advancing pregnancy probably because of increase in estrogen levels. ${ }^{1}$ Fibrinogen decreases in PPH indicating derangements in coagulation pathways.

Previous studies investigated serum fibrinogen and
PPH to establish ${ }^{2-4}$ or refute a prediction model between them ${ }^{3,5-7}$. The evidence for either hypothesis has remained weak because of conflicting findings. We questioned whether a pregnancy specific trigger/ hormonal disturbance influence both uterus tone and hemostasis of terminal pregnancy. For PPH subjects with atonic uterus, the fibrinogen levels will then be lowered predelivery. In subjects where PPH is not present, the fibrinogen levels will maintain a specific threshold level. We devised this comparative study between predelivery serum fibrinogen levels in vaginal delivery without PPH and with PPH. We hypothesized that predelivery serum

Received: $10^{\text {th }}$ September 2019. Accepted: $18^{\text {th }}$ November 2019.

Agarwal R, Jaiswal N, Kar R, Singh A, Srivastava H. Is serum fibrinogen an affirmative marker for vaginal delivery without PPH. The New Indian Journal of OBGYN. 2020; 6(2): 113-8. 
fibrinogen be used as positive alert marker for maternal well being and a conception ending with 'physiological' blood loss rather than envisage a PPH.

\section{Methods}

The study was conducted in tertiary health care institution of a low income Indian subcontinent country in joint collaboration with Department of Obstetrics and Gynecology and Department of Biochemistry from November 2016 to April 2018. Institutional Ethical clearance and informed patient consent was obtained for the study.

Sample size estimation

In a study by Niepraschk-von Dollen et al, predelivery fibrinogen in severe PPH and without severe PPH, there was a standard deviation of fibrinogen level i.e. $0.75 \mathrm{~g} / \mathrm{L}$ in control group and $0.8 \mathrm{~g} / \mathrm{L}$ in severe $\mathrm{PPH}^{2}$ Considering $\alpha=5 \%$ and power $=80 \%$ to estimate a difference of 0.8 units in fibrinogen levels, minimum sample of 15 cases were required in each group. ${ }^{2}$ As prevalence of severe PPH in our hospital and other studies is around 3\% of vaginal deliveries, for minimum 15 cases of severe PPH, we needed 500 subjects for the study. ${ }^{2}$

Inclusion and exclusion criteria

For study enrolment, we included low-risk pregnant women between age group 18-40 years presenting with singleton pregnancy after 24 weeks of gestation. We excluded patients with possible obstetric risks (altered coagulation profile, hemoglobin $<10 \mathrm{~g} / \mathrm{dl}$ or thrombocytopenia $\left(<10^{5} / \mathrm{mm}^{3}\right)$, hypertension, gestational diabetes and cholestasis. Predelivery blood samples were collected in these subjects on admission to the delivery suite when they presented with spontaneous labour and preserved for biochemical analysis. The subjects were then followed prospectively for spontaneous vaginal delivery. Patients requiring induction of delivery, instrumental or surgical delivery, with placental abruption or previa, with significant genital tract trauma or requiring manual removal of placenta were further excluded. A total of 453 subjects underwent spontaneous vaginal delivery and were eligible for fibrinogen estimation (figure 1). Due to limitation of financial resources, fibrinogen was finally estimated in 40 consecutive patients with PPH (rate limiting parameter) and equal number of non- $\mathrm{PPH}$ deliveries (random selection by computer generated numbers).

\section{Blood loss estimation}

The blood loss at delivery was measured using an impermeable collection bag placed under the patient's buttock and blood loss measurement was done by using a graduated jar (episiotomy was packed separately). Further, any sponges if used, were weighed separately using weighing scale and corresponding blood loss added. According to blood loss estimated, subjects were divided into three delivery groups (WHO definition) ${ }^{8}$ :

Non-PPH: Subjects with blood loss $<500 \mathrm{ml}$.

Mild PPH: Cases with atonic PPH $\geq 500 \mathrm{ml}$ and $\leq 1000 \mathrm{ml}$.

Severe PPH: Cases with atonic PPH $>1000 \mathrm{ml}$ with sign and symptoms of shock.

All the subjects were followed up intensively and PPH was managed as per established hospital standard treatment protocols.

\section{Method of serum fibrinogen estimation}

$2 \mathrm{ml}$ of blood collected in a plain vial was allowed to clot. It was then centrifuged at $5000 \mathrm{rpm}$ for 5 minutes. The supernatant serum was divided into two aliquots in Eppendorf fuses and stored at $-70^{\circ} \mathrm{C}$ for further analysis. Estimation of serum fibrinogen was done using ELISA kit.

\section{Statistical analysis}

Normality of the data was ensured using Levene's variance test. All quantitative parameters were expressed as mean \pm standard deviation (SD). Non-PPH versus PPH fibrinogen levels and mild versus severe $\mathrm{PPH}$ were compared using unpaired student $t$ test. A $p \leq 0.05$ was considered significant. Fibrinogen levels and association with blood loss was determined using logistic regression. Correlation between serum fibrinogen and blood loss was derived using Pearson's correlation. The fibrinogen thresholds for non-PPH were determined using the ROC plots.

\section{Results}

Final biochemical analysis of fibrinogen was possible in 80 subjects (40 without PPH and $40 \mathrm{PPH}$ deliveries). Within PPH group, there were 20 mild and 20 severe blood loss deliveries. The two main groups were similar when matched for maternal characteristics of age, BMI, mean arterial pressure, predelivery hemoglobin, and gestational age (Table 1). Mean blood loss in non-PPH and $\mathrm{PPH}$ group was $337.8 \pm 48 \mathrm{ml}$ and $941.0 \pm 393 \mathrm{ml}$ 
Table 1: Patient characteristics $(\mathrm{N}=\mathbf{8 0})$

\begin{tabular}{llll}
\hline Characteristics & Non PPH & PPH & p value* \\
\hline Age (years) mean \pm SD & $26 \pm 4$ & $25 \pm 4$ & 0.66 \\
Body mass index (BMI) at recruitment $\left(\mathrm{kg} / \mathrm{m}^{2}\right)$ & $24.55 \pm 1.96$ & $23.85 \pm 2.19$ & 0.13 \\
Mean arterial pressure $(\mathrm{mmHg})$ & $86.95 \pm 5.30$ & $89.13 \pm 5.50$ & 0.07 \\
Predelivery hemoglobin $(\mathrm{gm} \%)$ & $10.62 \pm 0.435$ & $10.78 \pm 0.63$ & 0.19 \\
Gestational age (weeks) & $37.25 \pm 1.21$ & $37.5 \pm 1.28$ & 0.37 \\
\hline$*$ p value $\leq 0.05$ has been considered as significant. & & &
\end{tabular}

respectively ( $\mathrm{p}=0.00$ ). With mild $\mathrm{PPH}$, the blood loss was $590.5 \pm 69 \mathrm{ml}$ which increased to $1292.5 \pm 231 \mathrm{ml}$ in severe PPH.

The serum fibrinogen levels in non-PPH group was
The serum fibrinogen as a positive marker for non-PPH is shown in table 3 and figures 1,2,3.

There were no PPH cases when serum fibrinogen level was $>2.63 \mathrm{~g} / \mathrm{L}$ (sensitivity $82.5 \%$, specificity $100 \%$ ). With fibrinogen levels $>1.07 \mathrm{~g} / \mathrm{L}$, the sensitivity was $100 \%$ and specificity $65 \%$. When a ROC was plotted for fibrinogen levels for non-PPH group, the area under curve was 0.976 (Figure 1).

\section{Discussion}

We determined serum $2.80 \pm 0.55 \mathrm{~g} / \mathrm{L}$ and $\mathrm{PPH}$ was $1.07 \pm 0.48 \mathrm{~g} / \mathrm{L}(\mathrm{p}<0.001)$. The fibrinogen levels were again significantly different when non-PPH was compared with mild $(1.19 \pm 0.31 \mathrm{~g} / \mathrm{L})$ or severe PPH group $(0.95 \pm 0.59 \mathrm{~g} / \mathrm{L})$. The difference in mild and severe PPH fibrinogen levels was however not

Table 3: ROC curve for fibrinogen levels in various groups.

\begin{tabular}{lllll}
\hline Group & AUC & Fibrinogen levels & Sensitivity & Specificity \\
\hline Non PPH versus overall PPH & 0.976 & $>2.63 \mathrm{~g} / \mathrm{L}$ & $82.5 \%$ & $100 \%$ \\
(Figure 1) & & $>1.07 \mathrm{~g} / \mathrm{L}$ & $100 \%$ & $65 \%$ \\
Non PPH versus mild PPH & 0.968 & $>2.21 \mathrm{~g} / \mathrm{L}$ & $92.5 \%$ & $100 \%$ \\
(Figure 2) & & $>1.07 \mathrm{~g} / \mathrm{L}$ & $100 \%$ & $60 \%$ \\
Non PPH versus severe PPH & 0.985 & $>2.64 \mathrm{~g} / \mathrm{L}$ & $80 \%$ & $100 \%$ \\
(Figure 3) & & $>1.05 \mathrm{~g} / \mathrm{L}$ & $100 \%$ & $90 \%$ \\
\hline
\end{tabular}

fibrinogen levels in women who could deliver without $\mathrm{PPH}$ and compared them with $\mathrm{PPH}$ deliveries ('PPH' group). The fibrinogen levels were significantly different in non-PPH (2.80g/L \pm 5.49$)$ versus $\mathrm{PPH}(1.07 \mathrm{~g} / \mathrm{L} \pm 4.78)$ vaginal deliveries $(\mathrm{p}<0.001)$.

The maternal coagulation profile alters during pregnancy to cope with the physiological process of delivery and minimize blood loss. The fibrinogen levels first increase through the first to third trimester. During $\mathrm{PPH}$, the fibrinogen levels deplete rapidly either because of the blood loss itself or the consumption of factors following activation of coagulation pathways. $^{3}$

The exact reasons for fibrinogen decline in PPH group remain unknown. The lowering of fibrinogen levels in $\mathrm{PPH}$ is a finding noted by previous several researchers ${ }^{2-4}$ although contrary observations also mentioned ${ }^{5-7}$. Charbit et al found that among several factors (fibrinogen, factor $\mathrm{V}$, antithrombin activity, protein $\mathrm{C}$ antigen) which decline during $\mathrm{PPH}$, only fibrinogen was associated with occurrence of severe $\mathrm{PPH}^{3}$ Cortet et al study derived 
fibrinogen level as an independent factor associated with PPH severity. ${ }^{3}$ Yamada et al reported an increasing blood loss with decreasing antenatal fibrinogen levels. ${ }^{4}$ They

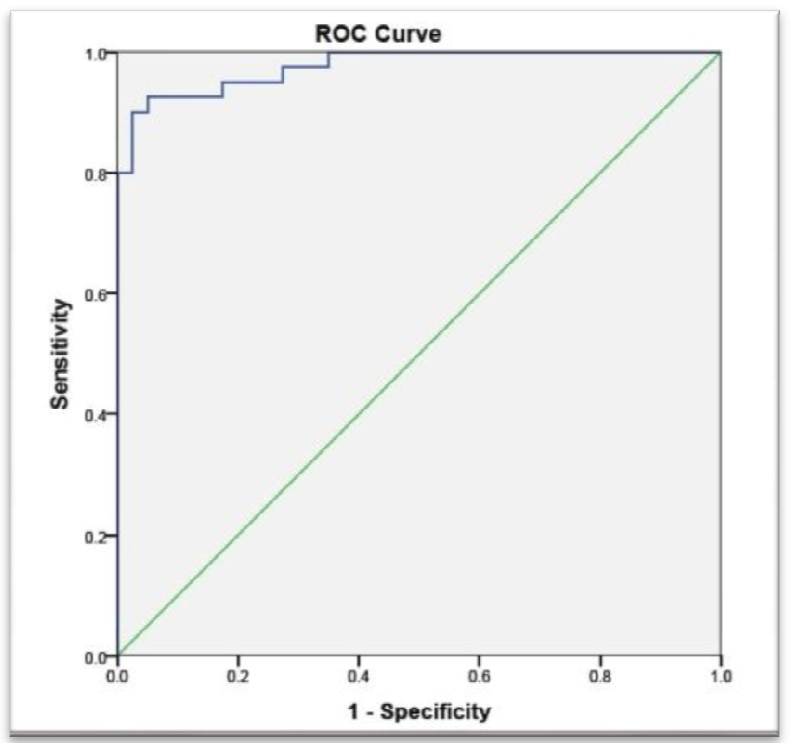

Figure 1: AUC curve for fibrinogen levels in non-PPH versus PPH group

also found a lowered fibrinogen concentration in women with PPH than those without it. Another important inference from their study was that $\mathrm{PPH}$ occurred significantly more in women with fibrinogen concentrations $<3.3 \mathrm{~g} / \mathrm{L} .{ }^{4}$ Niepraschk-von Dollen et al had

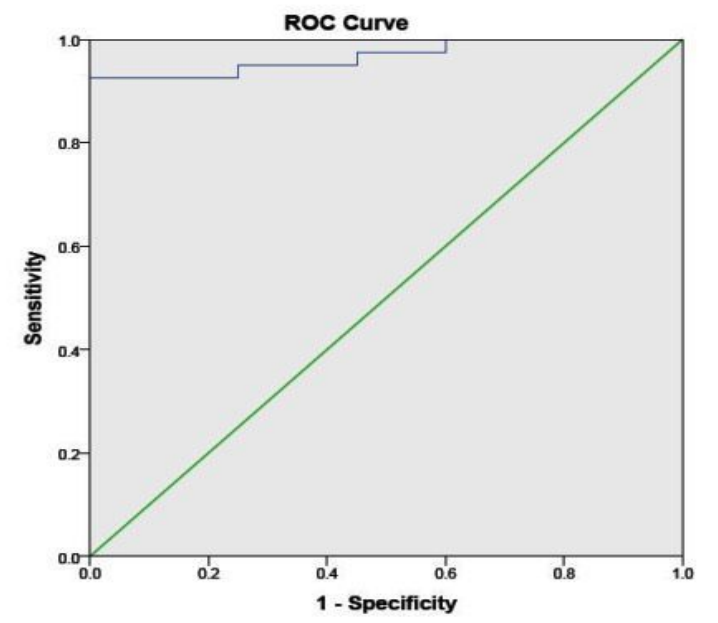

Figure 2: AUC curve for fibrinogen levels in non-PPH versus mild PPH deliveries studied predelivery fibrinogen levels and used PPH definitions similar to ours and found the levels significantly lower in women with severe PPH (4.22 \pm 0.82 $\mathrm{g} / \mathrm{L})$ than without severe PPH $(4.67 \pm 0.75 \mathrm{~g} / \mathrm{L})(\mathrm{p}=0.004)$. However, the series had no significant difference in PPH and non-PPH group. ${ }^{2}$

Pregnancy is a state of balanced hypercoagulability with fibrinogen levels (along with other adaptations of hemostasis) reaching a peak in third trimester of

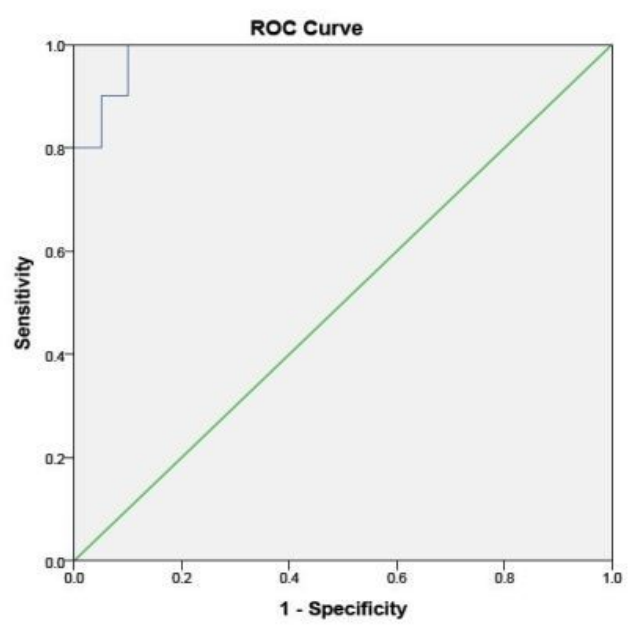

Figure 3: AUC curve for fibrinogen levels in non-PPH versus severe PPH deliveries

pregnancy induced by oestrogen. ${ }^{3}$ In the terminal stages of pregnancy, the body prepares for separation of placenta. A relative state of impaired hemostasis/ lowered fibrinogen may facilitate this. The resultant bleeding is however quickly taken care by the tonic uterus of a physiological pregnancy. For PPH cases, it appears that the specific trigger/ hormonal balance regulating the terminal pregnancy sequence is somewhat altered. The coagulation factor depletion cascade may thus initiate early. It is also possible that the same trigger may regulate both uterus tone and hemostasis of terminal pregnancy. Several authors have refuted the above observations and described that fibrinogen level was not found correlating with $\mathrm{PPH}^{5-7}$ It is to be reiterated that PPH etiology may be multifactorial, compensatory mechanisms may play a role and the precise critical fibrinogen levels responsible 
for physiological/ PPH delivery remain far from being established.

The timing of fibrinogen estimation is also important. Fibrinogen levels typically lie in range of $\sim 5 \mathrm{~g} / \mathrm{L}$ in the $3^{\text {rd }}$ trimester. ${ }^{3}$ The predelivery levels of fibrinogen depicting the PPH vary widely $(<2-4 \mathrm{~g} / \mathrm{L}) .^{3}$ These variations probably arise of different blood loss definitions used, sampling timings and severity of PPH predicted. Simon et al measured fibrinogen levels at delivery to predict PPH $(<2.9 \mathrm{~g} / \mathrm{L}$; sensitivity $19.6 \%$, specificity $97.8 \%)$ whereas the sampling was done during initial phase of PPH in Charbit et al study $(<4 \mathrm{~g} / \mathrm{L}$; sensitivity $74 \%$, specificity $65 \%) .{ }^{3}$ Cortet et al defined two cut offs for fibrinogen levels ( $<2 \mathrm{~g} / \mathrm{L}$; sensitivity $12.4 \%$, specificity $99.3 \%)(<3$ $\mathrm{g} / \mathrm{L}$; sensitivity $35.5 \%$, specificity $89.9 \%)^{3}{ }^{3}$

Clearly, a predictive model to forecast PPH using the predelivery fibrinogen would have been ideal. However, such attempts have not provided any conclusive evidence till date. ${ }^{1-7}$ We believed that if same trigger controls both uterus tone and hemostasis, then predelivery fibrinogen could be used as marker for maternal well being rather than predicting $\mathrm{PPH}$. We therefore devised this prospective case control study to determine critical predelivery serum fibrinogen levels that could possibly indicate a vaginal delivery without PPH. Our study contributes towards threshold of fibrinogen for replacement therapy as there is no consensus till now. The critical predelivery fibrinogen levels determined above can be used to monitor a pregnancy with 'physiological' coagulation changes and alert when 'PPH' derangements set in. In other words, the serial monitoring of serum fibrinogen levels antenatally can possibly guide to timely interventions for maternal blood loss. The Royal College of Obstetrics and Gynecologists recommends cryoprecipitates for fibrinogen $<1 \mathrm{~g} / \mathrm{L}$ and others recommend $<2 \mathrm{~g} / \mathrm{L}$ for optimal clot formation. ${ }^{9}$

Although the exact pathophysiology of coagulation alterations in pregnancy and its relationship with PPH still unknown, the fibrinogen remains a principal component of final stage of clot formation from both intrinsic and extrinsic coagulation cycles. The exact threshold and true correlation of fibrinogen to PPH needs more research. The research should involve various clinical settings and standardization of sample collection.
The main limitation of our study was the efficacy of monitoring fibrinogen levels in pregnancy care bundle has not yet been evaluated. The serial evaluations of the fibrinogen were also not done for this study. The strengths of our study were a matched cohort of pregnant women with normal coagulation profile followed prospectively for occurrence of PPH after collection of serum fibrinogen antenatally. All enrolled cases were non highrisk pregnancies eliminating the possible predisposing factors for PPH. All had delivered vaginally, hence confounding factors were kept to minimal. Besides a robust sample size in both mild and severe PPH groups, this study also gathered information on fibrinogen levels in pregnancy from Indian subcontinent for the first time.

\section{Conclusion}

Prenatal serum fibrinogen levels above $2.6 \mathrm{~g} / \mathrm{L}$ (sensitivity $82.5 \%, \quad$ specificity $100 \%$ ) indicated progression to an uneventful non-PPH vaginal delivery. Prenatal serum fibrinogen is suggested as potential alert marker for maternal well being (with non-PPH) in vaginal delivery.

\section{Conflict of interest: None. Disclaimer: Nil.}

\section{References}

1. Samama CM, Ickx B, Ozier Y, Steib A, Susen S, Godier A. The place of fibrinogen concentrates in the management of perioperative bleeding: A position paper from the Francophone Working Group on Perioperative Haemostasis (GIHP). Anaesth Crit Care Pain Med. 2018; 37: 355-65.

2. Niepraschk-von Dollen K, Bamberg C, Henkelmann A, Mickley L, Kaufner L, Henrich W, Pauly F. Predelivery maternal fibrinogen as a predictor of blood loss after vaginal delivery. Arch Gynecol Obstet. 2016; 294:74551.

3. Wikkelsø AJ. The role of fibrinogen and haemostatic assessment in postpartum haemorrhage: preparations for a randomised controlled trial. Dan Med J. 2015; 62: B5055.

4. Yamada T, Akaishi R, Oda Y, Nishida R, Yamada T, Ishikawa $\mathrm{S}$, et al. Antenatal fibrinogen concentrations and postpartum haemorrhage. Int J Obstet Anesth. 2014; 23: 365-70.

5. Kaufner L, Henkelmann A, von Heymann C, Feldheiser A, Mickley L, Niepraschk-von Dollen K, et al. Can 
The New Indian Journal of OBGYN. 2020 (January-June); 6(2)

prepartum thromboelastometry-derived parameters and fibrinogen levels really predict postpartum hemorrhage? J Perinat Med. 2017; 45: 427-35.

6. Karlsson O, Jeppsson A, Thornemo M, Lafrenz H, Rådström M, Hellgren M. Fibrinogen plasma concentration before delivery is not associated with postpartum haemorrhage: a prospective observational study. Br J Anaesth. 2015; 115: 99104.

7. Shibata Y, Shigemi D, Ito M, Terada K, Nakanishi $\mathrm{K}$, Kato $\mathrm{M}$, et al. Association between fibrinogen levels and severity of postpartum hemorrhage in singleton vaginal deliveries at a Japanese perinatal center. J Nippon Med Sch. 2014; 81: 94-6.

8. WHO. Recommendations for prevention and treatment of postpartum haemorrhage. Geneva: WHO; 2015.https://www.who.int/ reproductive health/ publications/maternal_perinatal_health/9789241548502 /en/, update 2018.

9. Mavrides E, Allard S, Chandraharan E, Collins P, Green $\mathrm{L}$, Hunt BJ, et al. Prevention and management of postpartum haemorrhage. BJOG. 2016; 124: e106-e149.

Rachna Agarwal ${ }^{1}$, Neha Jaiswal ${ }^{2}$, Rajarshi Kar ${ }^{3}$, Alpana Singh ${ }^{4}$, Himsweta Srivastava ${ }^{5}$

${ }^{1}$ Professor, ${ }^{2}$ Postgraduate student, ${ }^{4}$ Associate

Professor, ${ }^{5}$ Assistant Professor, Department of

Obstetrics \& Gynaecology; ${ }^{3}$ Associate Professor, Department of Biochemistry, University College of Medical Sciences \& Guru Teg Bahadur, Delhi 